\title{
Schrifttum und abgekürzt zitierte Literatur
}

Das Schrifttum zum Kernstrafrecht sowie sämtliche strafrechtlich relevanten Festschriften und vergleichbare Werke finden sich unter 1. Es folgt in alphabetischer Reihenfolge das Schrifttum zum Nebenstrafrecht und zu nichtstrafrechtlichen Gebieten: 2. Betäubungsmittelstrafrecht, 3. Bürgerliches Recht einschließlich Versicherungsrecht, 4. DDR-Strafrecht, 5. Europäisches Recht, 6. Handelsrecht einschließlich Bilanz- und Gesellschaftsrecht, 7. Jugendstrafrecht, 8. Kriminologie, 9. Ordnungswidrigkeitenrecht, 10. Presserecht, 11. Rechtshilfe, 12. Rechtsmedizin und Medizinstrafrecht, 13. Strafprozess- und Strafvollzugsrecht, 14. Straßenverkehrsrecht, 15. Verfassungsrecht und Verwaltungsrecht, 16. Wettbewerbs- und Kartellrecht, 17. Wirtschafts- und Steuerstrafrecht, 18. Zivilprozess- und Insolvenzrecht, 19. Sonstiges (einschließlich Arbeits- und Sozialrecht, Völkerrecht und Waffenrecht).

\section{Strafrecht (StGB) und Festschriften}

Zitier-Abk.

AK

Ambos

AnwK

Appel

Arzt/Weber/

Heinrich/Hilgendorf BT

v. Bar

Baumann

Baumann/Weber/Mitsch/

Eisele

BeckOK

Beling

Beulke-Symposion

Binding, Grundriß

Binding, Handbuch

Binding, Lehrbuch I, II

Binding, Normen

BK

Blei I, II

Bochumer Erläuterungen

Bockelmann BT 1, 2, 3

Bockelmann/Volk

Bringewat

Bruns, Strafzumessungsrecht

Bruns/Güntge

Bruns, Reflexionen

Burgstaller

Coimbra-Symposium

Dahs
Werk

Kommentar zum Strafgesetzbuch - Reihe Alternativkommentare, hrsg. v. Wassermann, Bd. 1 (1990), Bd. 3 (1986)

Internationales Strafrecht, 5. Aufl. (2018)

AnwaltKommentar StGB, hrsg. v. Leipold/Tsambikakis/Zöller, 2. Aufl. (2015)

Verfassung und Strafe (1998)

Strafrecht, Besonderer Teil, Lehrbuch, 3. Aufl. (2015)

Gesetz und Schuld im Strafrecht, 1. Bd. (1906), 2. Bd. (1907), 3. Bd. (1909)

Strafrecht, Allgemeiner Teil, 7. Aufl. (1975)

Strafrecht, Allgemeiner Teil, Lehrbuch, 12. Aufl. (2016)

Beck'scher Online-Kommentar StGB, hrsg. v. von Heintschel-Heinegg,

42. Edition (2019)

Die Lehre vom Verbrechen (1906)

Strafverteidigung - Grundlagen und Stolpersteine, Symposion für Werner Beulke, hrsg. v. Engländer/Fahl/Satzger/Swoboda (2012)

Grundriß des Deutschen Strafrechts, Allgemeiner Teil, 8. Aufl. (1913)

Handbuch des Strafrechts (1885)

Lehrbuch des gemeinen Deutschen Strafrechts, Besonderer Teil, 2. Aufl.

Bd. 1 (1902), Bd. 2 (1904/05)

Die Normen und ihre Übertretung, 2. Aufl., 4 Bände (1890 -1919)

Basler Kommentar Strafrecht I und II, hrsg. von Niggli/Wiprächtiger, 4. Aufl. (2018) (s. aber auch 15. Verfassungsrecht)

Strafrecht I, Allgemeiner Teil, 18. Aufl. (1983); Strafrecht II, Besonderer

Teil, 12. Aufl. (1983)

Bochumer Erläuterungen zum 6. Strafrechtsreformgesetz, hrsg. v. Schlüchter (1998)

Strafrecht, Besonderer Teil, Bd. 1: Vermögensdelikte, 2. Aufl. (1982); Bd. 2: Delikte gegen die Person (1977); Bd. 3: Ausgewählte Delikte gegen Rechtsgüter der Allgemeinheit (1980)

Strafrecht, Allgemeiner Teil, 4. Aufl. (1987)

Grundbegriffe des Strafrechts, 3. Aufl. (2018)

Strafzumessungsrecht: Gesamtdarstellung, 2. Aufl. (1974)

Das Recht der Strafzumessung, 3. Aufl. (2018) (vormals Bruns)

Neues Strafzumessungsrecht? „Reflexionen“ über eine geforderte Umgestaltung (1988)

Das Fahrlässigkeitsdelikt im Strafrecht (1974)

s. Schünemann/de Figueiredo Dias

Handbuch des Strafverteidigers, 8. Aufl. (2015) 
Dalcke/Fuhrmann/Schäfer Strafrecht und Strafverfahren, 37. Aufl. (1961)

Dölling/Duttge/König/Rössner s. HK-GS

Ebert

Ebert AT

Einführung 6. StrRG

Eisele BT 1, BT 2

Erbs/Kohlhaas

Erinnerungsgabe Grünhut

Eser et al., Rechtfertigung und Entschuldigung I-IV

Festgabe BGH 25

Festgabe BGH 50

Festgabe Frank

Festgabe Graßhoff

Festgabe Kern

Festgabe Paulus

Festgabe Peters

Festgabe RG I-VI

Festgabe Schultz

Festgabe Schweizer JT

Festschrift Achenbach

Festschrift Amelung

Festschrift Androulakis

Festschrift Augsburg

Festschrift Baumann

Festschrift Bemmann

Festschrift Beulke

Festschrift BGH 50

Festschrift Blau

Festschrift Bockelmann

Festschrift Böhm

Festschrift Böttcher

Festschrift Boujong

Festschrift Brauneck

Festschrift Bruns

Festschrift Burgstaller

Festschrift v. Caemmerer

Aktuelle Probleme der Strafrechtspflege: Beiträge anläßlich eines Symposiums zum 60. Geburtstag von E. W. Hanack, hrsg. v. Ebert (1991)

Strafrecht, Allgemeiner Teil, 4. Aufl. (2001)

Einführung in das 6. Strafrechtsreformgesetz (1998) (bearb. v. Dencker u.a.)

Strafrecht - Besonderer Teil I: Straftaten gegen die Person und die Allge-

meinheit; Strafrecht - Besonderer Teil II: Eigentumsdelikte, Vermögensde-

likte und Urkundendelikte 5. Aufl. (2019)

Strafrechtliche Nebengesetze, Loseblattausgabe, 224. Aufl. (2019ff)

Erinnerungsgabe für Max Grünhut (1965)

Rechtfertigung und Entschuldigung: rechtsvergleichende Perspektiven.

Beiträge aus dem Max-Planck-Institut für ausländisches und internationales Strafrecht, Bd. 1, hrsg. v. Eser/Fletcher (1987); Bd. 2, hrsg. v. Eser/

Fletcher (1988); Bd. 3: Deutsch-Italienisch-Portugiesisch-Spanisches Strafrechtskolloquium 1990 in Freiburg, hrsg. v. Eser/Perron (1991); Bd. 4: Ostasiatisch-Deutsches Strafrechtskolloquium 1993 in Tokio, hrsg. v. Eser/ Nishihara (1995)

25 Jahre Bundesgerichtshof

50 Jahre Bundesgerichtshof, Festgabe aus der Wissenschaft, Band IV:

Straf- und Strafprozeßrecht (2000)

Festgabe für Reinhard von Frank zum 70. Geburtstag, 2 Bde. (1930)

Der verfasste Rechtsstaat, Festgabe für Karin Graßhoff (1998)

Festgabe für Eduard Kern zum 70. Geburtstag (1957)

Festgabe für Rainer Paulus zum 70. Geburtstag (2009)

Wahrheit und Gerechtigkeit im Strafverfahren: Festgabe für Karl Peters aus Anlaß seines 80. Geburtstages (1984)

Die Reichsgerichtspraxis im deutschen Rechtsleben: Festgabe der juristischen Fakultäten zum 50-jährigen Bestehen des Reichsgerichts (1929)

Lebendiges Strafrecht: Festgabe zum 65. Geburtstag von Hans Schultz (1977)

Festgabe zum Schweizerichen Juristentag (1963)

Festschrift für Hans Achenbach zum 70. Geburtstag (2011)

Grundlagen des Straf- und Strafverfahrensrechts: Festschrift für Knut Amelung zum 70. Geburtstag (2009)

Festschrift für Nikolaos Androulakis zum 70. Geburtstag (2003)

Recht in Europa: Festgabe zum 30-jährigen Bestehen der Juristischen

Fakultät Augsburg (2002)

Festschrift für Jürgen Baumann zum 70. Geburtstag (1992)

Festschrift für Günter Bemmann zum 70. Geburtstag (1997)

Ein menschengerechtes Strafrecht als Lebensaufgabe - Festschrift für

Werner Beulke zum 70. Geburtstag (2015)

Festschrift aus Anlaß des fünfzigjährigen Bestehens von Bundesgerichtshof, Bundesanwaltschaft und Rechtsanwaltschaft beim Bundesgerichtshof (2000)

Festschrift für Günter Blau zum 70. Geburtstag (1985)

Festschrift für Paul Bockelmann zum 70. Geburtstag (1979)

Festschrift für Alexander Böhm zum 70. Geburtstag (1999)

Festschrift für Reinhard Böttcher zum. 70 Geburtstag (2007)

Verantwortung und Gestaltung: Festschrift für Karlheinz Boujong zum

65. Geburtstag (1996)

Ehrengabe für Anne-Eva Brauneck (1999)

Festschrift für Hans-Jürgen Bruns zum 70. Geburtstag (1978)

Festschrift für Manfred Burgstaller zum 65. Geburtstag (2004)

Festschrift für Ernst von Caemmerer zum 70. Geburtstag (1978) 
Festschrift Celle I

Festschrift Celle II

Festschrift Dahs

Festschrift Dencker

Festschrift Diestelkamp

Festschrift DJT

Festschrift Dreher

Festschrift Dünnebier

Festschrift Eisenberg

Festschrift Engisch

Festschrift Ermacora

Festschrift Eser

Festschrift Europa-Institut

Festschrift Fezer

Festschrift Fiedler

Festschrift Friebertshäuser

Festschrift Frisch

Festschrift Fuchs

Festschrift GA

Festschrift Gallas

Festschrift von Gamm

Festschrift Gauweiler

Festschrift Geerds

Festschrift Geilen

Festschrift Geiß

Festschrift Geppert

Festschrift Germann

Festschrift Gleispach

Festschrift Göppinger

Festschrift Gössel

Festschrift Grünwald

Festschrift Grützner

Festschrift Hamm

Festschrift Hanack

Festschrift Hanauer

Festschrift Hassemer

Festschrift Heidelberg
Göttinger Festschrift für das Oberlandesgericht Celle: zum 250-jährigen

Bestehen des Oberlandesgerichts Celle (1961)

Festschrift zum 275-jährigen Bestehen des Oberlandesgerichts Celle (1986)

Festschrift für Hans Dahs zum 70. Geburtstag (2005)

Festschrift für Friedrich Dencker zum 70. Geburtstag (2012)

Geschichte der Zentraljustiz in Mitteleuropa: Festschrift für Bernhard Diestelkamp zum 65. Geburtstag (1994)

Hundert Jahre deutsches Rechtsleben: Festschrift zum hundertjährigen

Bestehen des Deutschen Juristentages 1860 -1960, 2 Bde. (1960)

Festschrift für Eduard Dreher zum 70. Geburtstag (1977)

Festschrift für Hans Dünnebier zum 75. Geburtstag (1982)

Festschrift für Ulrich Eisenberg zum 70. Geburtstag (2009)

Festschrift für Karl Engisch zum 70. Geburtstag (1969)

Fortschritt im Bewußtsein der Grund- und Menschenrechte: Festschrift für Felix Ermacora zum 65. Geburtstag (1988)

Menschengerechtes Strafrecht: Festschrift für Albin Eser zum 70. Geburtstag (2005)

Europäische Integration und Globalisierung, Festschrift zum 60-jährigen Bestehen des Europa-Instituts (2011)

Festschrift für Gerhard Fezer zum 70. Geburtstag (2008)

Verfassung - Völkerrecht - Kulturgüterschutz, Festschrift für Wilfried

Fiedler zum 70. Geburtstag (2011)

Festgabe für den Strafverteidiger Dr. Heino Friebertshäuser (1997)

Grundlagen und Dogmatik des gesamten Strafrechtssystems - Festschrift

für Wolfgang Frisch zum 70. Geburtstag (2013)

Festschrift für Helmut Fuchs zum 65. Geburtstag (2014)

140 Jahre Goltdammer's Archiv für Strafrecht: eine Würdigung zum

70. Geburtstag von Paul-Günter Pötz (1993)

Festschrift für Wilhelm Gallas zum 70. Geburtstag (1973)

Festschrift für Otto-Friedrich Frhr. von Gamm

Recht und Politik: Festschrift für Peter Gauweiler zum 60. Geburtstag (2009)

Kriminalistik und Strafrecht: Festschrift für Friedrich Geerds zum 70. Geburtstag (1995)

Bochumer Beiträge zu aktuellen Strafrechtsthemen: Festschrift für Gerd

Geilen zum 70. Geburtstag (2003)

Festschrift für Karlmann Geiß zum 65. Geburtstag (2000)

Festschrift für Klaus Geppert zum 70. Geburtstag (2011)

Rechtsfindung - Beiträge zur juristischen Methodenlehre: Festschrift für

Oscar Adolf Germann zum 80. Geburtstag (1969)

Gegenwartsfragen der Strafrechtswissenschaft: Festschrift zum 60. Ge-

burtstag von Graf W. Gleispach (1936) (Nachdruck 1995)

Kriminalität, Persönlichkeit, Lebensgeschichte und Verhalten: Festschrift für Hans Göppinger zum 70. Geburtstag (1990)

Festschrift für Karl Heinz Gössel zum 70. Geburtstag (2002)

Festschrift für Gerald Grünwald zum 70. Geburtstag (1999)

Aktuelle Probleme des internationalen Strafrechts - Beiträge zur Gestaltung des internationalen und supranationalen Strafrechts: Heinrich Grützner zum 65. Geburtstag (1970)

Festschrift für Rainer Hamm zum 65. Geburtstag (2008)

Festschrift für Ernst-Walter Hanack zum 70. Geburtstag (1999)

Festschrift für Rudolf Hanauer aus Anlass seines 70. Geburtstages (1978)

Festschrift für Winfried Hassemer zum 70. Geburtstag (2010)

Richterliche Rechtsfortbildung: Festschrift der Juristischen Fakultät zur 600-Jahr-Feier der Universität Heidelberg (1986) 
Festschrift Heinitz

Festschrift

Heintschel-Heinegg

Festschrit Heinz

Festschrift Henkel

Festschrift v. Hentig

Festschrift Herzberg

Festschrift Herzog

Festschrift Heusinger

Festschrift Hilger

Festschrift Hirsch

Festschrift Honig

Festschrift Hruschka

Festschrift Hubmann

Festschrift Hübner

Festschrift Jakobs

Festschrift Jauch

Festschrift Jescheck

Festschrift Jung

Festschrift JurGes. Berlin

Festschrift Kaiser

Festschrift Kargl

Festschrift Arthur

Kaufmann (1989)

Festschrift Arthur

Kaufmann (1993)

Festschrift Kern

Festschrift Kerner

Festschrift Kirchberg

Festschrift Kleinknecht

Festschrift Klug

Festschrift Koch

Festschrift Kohlmann

Festschrift Kohlrausch

Festschrift Köln

Festschrift Krause

Festschrift Krey

Festschrift Küper

Festschrift Kühne

Festschrift Lackner
Festschrift für Ernst Heinitz zum 70. Geburtstag (1972)

Festschrift für Bernd von Heintschel-Heinegg zum 70. Geburtstag (2015)

Festschrift für Wolfgang Heinz zum 70. Geburtstag (2012)

Grundfragen der gesamten Strafrechtswissenschaft: Festschrift für Hein-

rich Henkel zum 70. Geburtstag (1974)

Kriminologische Wegzeichen: Festschrift für Hans v. Hentig zum 80. Geburtstag (1967)

Strafrecht zwischen System und Telos: Festschrift für Rolf Dietrich Herzberg zum 70. Geburtstag (2008)

Staatsrecht und Politik: Festschrift für Roman Herzog zum 75. Geburtstag (2009)

Ehrengabe für Bruno Heusinger (1968)

Datenübermittlungen und Vorermittlungen: Festgabe für Hans Hilger (2003)

Festschrift für Hans Joachim Hirsch zum 70. Geburtstag (1999)

Festschrift für Richard M. Honig zum 80. Geburtstag (1970)

Jahrbuch für Recht und Ethik: Festschrift für Joachim Hruschka zum

70. Geburtstag (2006)

Beiträge zum Schutz der Persönlichkeit und ihrer schöpferischen Leistung:

Festschrift für Heinrich Hubmann zum 70. Geburtstag (1985)

Festschrift für Heinz Hübner zum 70. Geburtstag (1984)

Festschrift für Günther Jakobs zum 70. Geburtstag (2007)

Wie würden Sie entscheiden? Festschrift für Gerd Jauch zum 65. Geburtstag (1990)

Festschrift für Hans-Heinrich Jescheck zum 70. Geburtstag, 2 Bde. (1985)

Festschrift für Heike Jung zum 65. Geburtstag (2007)

Festschrift zum 125-jährigen Bestehen der Juristischen Gesellschaft zu

Berlin (1984)

Internationale Perspektiven in Kriminologie und Strafrecht: Festschrift für

Günther Kaiser zum 70. Geburtstag, 2 Bde. (1998)

Festschrift für Walter Kargl zum 70. Geburtstag (2015)

Jenseits des Funktionalismus: Arthur Kaufmann zum 65. Geburtstag

(1989)

Strafgerechtigkeit: Festschrift für Arthur Kaufmann zum 70. Geburtstag (1993)

Tübinger Festschrift für Eduard Kern (1968)

Kriminologie - Kriminalpolitik - Strafrecht, Festschrift für Hans-Jürgen

Kerner zum 70. Geburtstag (2013)

Festschrift für Christian Kirchberg zum 70. Geburtstag (2017)

Strafverfahren im Rechtsstaat: Festschrift für Theodor Kleinknecht zum

75. Geburtstag (1985)

Festschrift für Ulrich Klug zum 70. Geburtstag, 2 Bde. (1983)

Strafverteidigung und Strafprozeß: Festgabe für Ludwig Koch (1989)

Festschrift für Günter Kohlmann zum 70. Geburtstag (2003)

Probleme der Strafrechtserneuerung: Eduard Kohlrausch zum 70. Geburtstage dargebracht (1944; Nachdruck 1978)

Festschrift der Rechtswissenschaftlichen Fakultät zur 600-Jahr-Feier der Universität zu Köln (1988)

Recht und Kriminalität: Festschrift für Friedrich-Wilhelm Krause zum

70. Geburtstag (1990)

Festschrift für Volker Krey zum 70. Geburtstag (2010)

Festschrift für Wilfried Küper zum 70. Geburtstag (2007)

Festschrift für Hans-Heiner Kühne zum 70. Geburtstag (2013)

Festschrift für Karl Lackner zum 70. Geburtstag (1987) 
Festschrift Lampe

Festschrift Lange

Festschrift Laufs

Festschrift Leferenz

Festschrift Lenckner

Festschrift Lüderssen

Festschrift Maihofer

Festschrift Maiwald

Festschrift Mangakis

Festschrift Maurach

Festschrift H. Mayer

Festschrift Mehle

Festschrift Meyer-Goßner

Festschrift Mezger

Festschrift Middendorff

Festschrift Miyazawa

Festschrift E. Müller (2003)

Festschrift E. Müller (2008)

Festschrift Müller-Dietz (1998) Das Recht und die schönen Künste: Heinz Müller-Dietz zum 65. Geburtstag (1998)

Festschrift Müller-Dietz (2001) Grundlagen staatlichen Strafens: Festschrift für Heinz-Müller-Dietz zum 70. Geburtstag (2001)

Festschrift Nehm

Festschrift Neumann

Festschrift Nishihara

Festschrift Nobbe

Festschrift Odersky

Festschrift Oehler

Festschrift Otto

Festschrift Paarhammer

Festschrift Paeffgen

Festschrift Pallin

Festschrift Partsch

Festschrift Peters

Festschrift Ch. Pfeiffer

Festschrift Pfeiffer

Festschrift Pfenniger

Jus humanum: Grundlagen des Rechts und Strafrechts, Festschrift für Ernst-Joachim Lampe zum 70. Geburtstag (2003)

Festschrift für Richard Lange zum 70. Geburtstag (1976)

Humaniora, Medizin - Recht - Geschichte: Festschrift für Adolf Laufs zum 70. Geburtstag (2006)

Kriminologie - Psychiatrie - Strafrecht: Festschrift für Heinz Leferenz zum 70. Geburtstag (1983)

Festschrift für Theodor Lenckner zum 70. Geburtstag (1998)

Festschrift für Klaus Lüderssen zum 70. Geburtstag (2002)

Rechtsstaat und Menschenwürde: Festschrift für Werner Maihofer zum

70. Geburtstag (1988)

Festschrift für Manfred Maiwald zum 75. Geburtstag (2011)

Strafrecht - Freiheit - Rechtsstaat: Festschrift für Georgios Mangakis (1999)

Festschrift für Reinhart Maurach zum 70. Geburtstag (1972)

Beiträge zur gesamten Strafrechtswissenschaft: Festschrift für Hellmuth

Mayer zum 70. Geburtstag (1966)

Festschrift für Volkmar Mehle zum 65. Geburtstag (2009)

Festschrift für Lutz Meyer-Goßner zum 65. Geburtstag (2001)

Festschrift für Edmund Mezger zum 70. Geburtstag (1954)

Festschrift für Wolf Middendorff zum 70. Geburtstag (1986)

Festschrift für Koichi Miyazawa: dem Wegbereiter des japanisch-deutschen Strafrechtsdiskurses (1995)

Opuscula Honoraria, Egon Müller zum 65. Geburtstag (2003)

Festschrift für Egon Müller zum 70. Geburtstag (2008)

Strafrecht und Justizgewährung: Festschrift für Kay Nehm zum 65. Geburtstag (2006)

Rechtsstaatliches Strafrecht: Festschrift für Ulfrid Neumann zum 70. Ge-

burtstag (2017)

Festschrift für Haruo Nishihara zum 70. Geburtstag (1998)

Entwicklungslinien im Bank- und Kapitalmarktrecht: Festschrift für Gerd

Nobbe zum 65. Geburtstag (2009)

Festschrift für Walter Odersky zum 65. Geburtstag (1996)

Festschrift für Dietrich Oehler zum 70. Geburtstag (1985)

Festschrift für Harro Otto zum 70. Geburtstag (2007)

In mandatis meditari, Festschrift für Hans Paarhammer zum 65. Geburtstag (2012)

Strafe und Prozess im freiheitlichen Rechtsstaat - Festschrift für Hans-

Ullrich Paeffgen zum 70. Geburtstag (2015)

Strafrecht, Strafprozeßrecht und Kriminologie: Festschrift für Franz Pallin zum 80. Geburtstag (1989)

Des Menschen Recht zwischen Freiheit und Verantwortung: Festschrift für Karl Josef Partsch zum 75. Geburtstag (1989)

Einheit und Vielfalt des Strafrechts: Festschrift für Karl Peters zum

70. Geburtstag (1974)

Kriminologie ist Gesellschaftswissenschaft, Festschrift für Christian Pfeiffer zum 70. Geburtstag (2014)

Strafrecht, Unternehmensrecht, Anwaltsrecht: Festschrift für Gerd Pfeiffer zum Abschied aus dem Amt als Präsident des Bundesgerichtshofes (1988)

Strafprozeß und Rechtsstaat: Festschrift zum 70. Geburtstag von

H. F. Pfenniger (1976) 
Festschrift Platzgummer Festschrift Pötz

Festschrift Puppe

Festschrift Rasch

Festschrift Rebmann

Festschrift Reichsgericht

Festschrift Reichsjustizamt

Festschrift Richterakademie

Festschrift Rieß

Festschrift Richter

Festschrift Rissing-van Saan

Festschrift Rittler

Festschrift Rolinski

Festschrift Rosenfeld

Festschrift Rössner

Festschrift Roxin (2001)

Festschrift Roxin (2011)

Festschrift Imme Roxin

Festschrift Rudolphi

Festschrift Salger

Festschrift Samson

Festschrift Sarstedt

Festschrift Sauer

Festschrift G. Schäfer

Festschrift K. Schäfer

Festschrift Schaffstein

Festschrift Schewe

Festschrift W. Schiller

Festschrift Schleswig-Holstein

Festschrift Schlüchter

Festschrift N. Schmid

Festschrift R. Schmid

Festschrift Eb. Schmidt

Festschrift Schmidt-Leichner

Festschrift Schmitt
Festschrift für Winfried Platzgummer zum 65. Geburtstag (1995)

s. Festschrift GA

Strafrechtswissenschaft als Analyse und Konstruktion: Festschrift für Ingeborg Puppe zum 70. Geburtstag (2011)

Die Sprache des Verbrechens - Wege zu einer klinischen Kriminologie:

Festschrift für Wilfried Rasch (1993)

Festschrift für Kurt Rebmann zum 65. Geburtstag (1989)

Die Reichsgerichtspraxis im deutschen Rechtsleben, Festgabe der juristischen Fakultäten zum 50-jährigen Bestehen des Reichsgerichts, Bd. 5, Strafrecht und Strafprozeß (1929)

Vom Reichsjustizamt zum Bundesministerium der Justiz, Festschrift zum 100-jährigen Gründungstag des Reichsjustizamtes am 1.1.1877 (1977)

Justiz und Recht: Festschrift aus Anlaß des 10-jährigen Bestehens der

Deutschen Richterakademie in Trier (1983)

Festschrift für Peter Rieß zum 70. Geburtstag (2002)

Verstehen und Widerstehen: Festschrift für Christian Richter II zum

65. Geburtstag (2006)

Festschrift für Ruth Rissing-van Saan zum 65. Geburtstag (2011)

Festschrift für Theodor Rittler zu seinem 80. Geburtstag (1957)

Festschrift für Klaus Rolinski zum 70. Geburtstag (2002)

Festschrift für Ernst Heinrich Rosenfeld zu seinem 80. Geburtstag (1949)

Über allem: Menschlichkeit - Festschrift für Dieter Rössner zum 70. Geburtstag (2015)

Festschrift für Claus Roxin zum 70. Geburtstag (2001)

Strafrecht als Scientia Universalis: Festschrift für Claus Roxin zum

80. Geburtstag (2011)

Festschrift für Imme Roxin zum 75. Geburtstag (2012)

Festschrift für Hans-Joachim Rudolphi zum 70. Geburtstag (2004)

Straf- und Strafverfahrensrecht, Recht und Verkehr, Recht und Medizin:

Festschrift für Hannskarl Salger zum Abschied aus dem Amt als Vize-

präsident des Bundesgerichtshofes (1995)

Recht - Wirtschaft - Strafe: Festschrift für Erich Samson zum 70. Geburts$\operatorname{tag}(2010)$

Festschrift für Werner Sarstedt zum 70. Geburtstag (1981)

Festschrift für Wilhelm Sauer zu seinem 70. Geburtstag (1949)

NJW-Sonderheft für Gerhard Schäfer zum 65. Geburtstag (2002)

Festschrift für Karl Schäfer zum 80. Geburtstag (1980)

Festschrift für Friedrich Schaffstein zum 70. Geburtstag (1975)

Medizinrecht - Psychopathologie - Rechtsmedizin: diesseits und jenseits der Grenzen von Recht und Medizin, Festschrift für Günter Schewe zum 60. Geburtstag (1991)

Festschrift für Wolf Schiller zum 65. Geburtstag (2014)

Strafverfolgung und Strafverzicht: Festschrift zum 125-jährigen Bestehen der Staatsanwaltschaft Schleswig-Holstein (1992)

Freiheit und Verantwortung in schwieriger Zeit: kritische Studien aus vorwiegend straf(prozeß)rechtlicher Sicht zum 60. Geburtstag von Ellen Schlüchter (1998)

Wirtschaft und Strafrecht: Festschrift für Niklaus Schmid zum 65. Geburts$\operatorname{tag}(2001)$

Recht, Justiz, Kritik: Festschrift für Richard Schmid zum 85. Geburtstag (1985)

Festschrift für Eberhard Schmidt zum 70. Geburtstag (1961)

Festschrift für Erich Schmidt-Leichner zum 65. Geburtstag (1977)

Festschrift für Rudolf Schmitt zum 70. Geburtstag (1992) 
Festschrift Schneider

Festschrift Schöch

Festschrift Schreiber

Festschrift Schroeder

Festschrift Schüler-Spr

Festschrift Schwind

Festschrift Schwinge

Festschrift Seebode

Festschrift Sendler

Festschrift Spendel

Festschrift Spinellis

Festschrift Steinhilper

Festschrift Stock

Festschrift Stöckel

Festschrift Stree/Wessels

Festschrift Stutte

Festschrift Tiedemann

Festschrift Trechsel

Festschrift Triffterer

Festschrift Tröndle

Festschrift Tübingen

Festschrift Venzlaff

Festschrift Volk

Festschrift Vormbaum

Festschrift Waseda

Festschrift Wassermann

Festschrift v. Weber

Festschrift Weber

Festschrift Welzel

Festschrift Widmaier

Festschrift Wolf

Festschrift Wolff

Festschrift Wolter

Festschrift Würtenberger
Kriminologie an der Schwelle zum 21. Jahrhundert: Festschrift für Hans Joachim Schneider zum 70. Geburtstag (1998)

Festschrift für Heinz Schöch zum 70. Geburtstag (2010)

Strafrecht, Biorecht, Rechtsphilosophie: Festschrift für Hans-Ludwig

Schreiber zum 70. Geburtstag (2003)

Festschrift für Friedrich-Christian Schroeder zum 70. Geburtstag (2006)

mFestschrift für Horst Schüler-Springorum zum 65. Geburtstag (1993)

Kriminalpolitik und ihre wissenschaftlichen Grundlagen: Festschrift für Hans-Dieter Schwind zum 70. Geburtstag (2006)

Persönlichkeit in der Demokratie: Festschrift für Erich Schwinge zum 70. Geburtstag (1973)

Festschrift für Manfred Seebode zum 70. Geburtstag (2008)

Bürger-Richter-Staat: Festschrift für Horst Sendler zum Abschied aus seinem Amt (1991)

Festschrift für Günter Spendel zum 70. Geburtstag (1992)

Die Strafrechtswissenschaft im 21. Jahrhundert: Festschrift für Dionysios Spinellis, 2 Bde. (2001)

Kriminologie und Medizinrecht: Festschrift für Gernot Steinhilper zum 70. Geburtstag (2013)

Studien zur Strafrechtswissenschaft: Festschrift für Ulrich Stock zum

70. Geburtstag (1966)

Strafrechtspraxis und Reform: Festschrift für Heinz Stöckel zum 70. Geburtstag (2010)

Beiträge zur Rechtswissenschaft: Festschrift für Walter Stree und Johannes Wessels zum 70. Geburtstag (1993)

Jugendpsychiatrie und Recht: Festschrift für Hermann Stutte zum 70. Geburtstag (1979)

Strafrecht und Wirtschaftsstrafrecht: Dogmatik, Rechtsvergleich, Rechtstatsachen; Festschrift für Klaus Tiedemann zum 70. Geburtstag (2008)

Strafrecht, Strafprozessrecht und Menschenrechte: Festschrift für Stefan

Trechsel zum 65. Geburtstag (2002)

Festschrift für Otto Triffterer zum 65. Geburtstag (1996)

Festschrift für Herbert Tröndle zum 70. Geburtstag (1989)

Tradition und Fortschritt im Recht: Festschrift gewidmet der Tübinger Juristenfakultät zu ihrem 500-jährigen Bestehen 1977 von ihren gegenwärtigen Mitgliedern (1977)

Forensische Psychiatrie - Entwicklungen und Perspektiven: Festschrift für Ulrich Venzlaff zum 85. Geburtstag (2006)

In dubio pro libertate: Festschrift für Klaus Volk zum 65. Geburtstag (2009)

Strafrecht und Juristische Zeitgeschichte - Symposium anlässlich des 70. Geburtstages von Thomas Vormbaum

Recht in Ost und West: Festschrift zum 30-jährigen Jubiläum des Instituts für Rechtsvergleichung der Waseda-Universität (1988)

Festschrift für Rudolf Wassermann zum 60. Geburtstag (1985)

Festschrift für Hellmuth von Weber zum 70. Geburtstag (1963)

Festschrift für Ulrich Weber zum 70. Geburtstag (2004)

Festschrift für Hans Welzel zum 70. Geburtstag (1974)

Strafverteidigung, Revision und die gesamten Strafrechtswissenschaften:

Festschrift für Gunter Widmaier zum 70. Geburtstag (2008)

Mensch und Recht: Festschrift für Erik Wolf zum 70. Geburtstag (1972)

Festschrift für E. A. Wolff zum 70. Geburtstag (1998)

Festschrift für Jürgen Wolter zum 70. Geburtstag (2013)

Kultur, Kriminalität, Strafrecht: Festschrift für Thomas Würtenberger zum 70. Geburtstag (1977) 
Festschrift Würtenberger II

Festschrift Würzburger

Juristenfakultät

Festschrift Zeidler

Festschrift Zoll

Festschrift Zweibrücken

Fischer

Forster/Joachim

Frank

Freiburg-Symposium

Freund AT

Frisch, Vorsatz und Risiko

Frisch, Tatbestandsmäßiges

Verhalten

Frister

Gallas, Beiträge

Gedächtnisschrift Delitala

Gedächtnisschrift

Armin Kaufmann

Gedächtnisschrift

H. Kaufmann

Gedächtnisschrift Keller

Gedächtnisschrift Meurer

Gedächtnisschrift K. Meyer

Gedächtnisschrift Noll

Gedächtnisschrift H. Peters

Gedächtnisschrift Radbruch

Gedächtnisschrift Schlüchter

Gedächtnisschrift Schröder

Gedächtnisschrift Seebode

Gedächtnisschrift Tjong

Gedächtnisschrift Vogler

Gedächtnisschrift Zipf

Gimbernat et al.

Gössel I, II

Gössel/Dölling

Gropp AT

Gropp Sonderbeteiligungen

Grundfragen

Haft AT, BT II

Haft/Hilgendorf BT I

Hanack-Symposium
Verfassungsstaatlichkeit im Wandel, Festschrift für Thomas Würtenberger zum 70. Geburtstag (2013)

Raum und Recht: Festschrift 600 Jahre Würzburger Juristenfakultät (2002) Festschrift für Wolfgang Zeidler (1987)

Rechtsstaat und Strafrecht: Festschrift für Andrzej Zoll zum 70. Geburtstag (2012)

175 Jahre Pfälzisches Oberlandesgericht: 1815 Appellationshof, Oberlandesgericht 1990 (1990)

Strafgesetzbuch und Nebengesetze, Kurzkommentar, 63. Aufl. (2016)

Alkohol und Schuldfähigkeit (1997)

Das Strafgesetzbuch für das Deutsche Reich nebst dem Einführungsgesetz, 18. Aufl. (1931)

s. Tiedemann

Strafrecht, Allgemeiner Teil, 2. Aufl. (2008)

Vorsatz und Risiko: Grundfragen des tatbestandsmäßigen Verhaltens und des Vorsatzes (1983)

Tatbestandsmäßiges Verhalten und Zurechnung des Erfolgs (1988)

Strafrecht Allgemeiner Teil, 8. Aufl. (2018)

Beiträge zur Verbrechenslehre (1968)

Gedächtnisschrift für (Studi in memoria di) Giacomo Delitala, 3 Bde. (1984)

Gedächtnisschrift für Armin Kaufmann (1989)

Gedächtnisschrift für Hilde Kaufmann (1986)

Gedächtnisschrift für Rolf Keller (2003)

Gedächtnisschrift für Dieter Meurer (2002)

Gedächtnisschrift für Karlheinz Meyer (1990)

Gedächtnisschrift für Peter Noll (1984)

Gedächtnisschrift für Hans Peters (1967)

Gedächtnisschrift für Gustav Radbruch (1968)

Gedächtnisschrift für Ellen Schlüchter (2002)

Gedächtnisschrift für Horst Schröder (1978)

Im Zweifel für die Freiheit: Gedächtnisschrift für Manfred Seebode (2015)

Gedächtnisschrift für Zong Uk Tjong (1985)

Gedächtnisschrift für Theo Vogler (2004)

Gedächtnisschrift für Heinz Zipf (1999)

Internationale Dogmatik der objektiven Zurechnung und der Unterlassungsdelikte: Spanisch-Deutsches Symposium zu Ehren von Claus Roxin, hrsg. v. Gimbernat et al. (1995)

Strafrecht, Besonderer Teil, Bd. 1: Delikte gegen immaterielle Rechtsgüter des Individuums, 2. Aufl. (1999); Bd. 2: Straftaten gegen materielle Rechtsgüter des Individuums (1996)

Strafrecht, Besonderer Teil, Bd. 1: Straftaten gegen Persönlichkeits- und Gemeinschaftswerte, 2. Aufl. (2004)

Strafrecht, Allgemeiner Teil, 4. Auflage (2015)

Deliktstypen mit Sonderbeteiligung (1992)

Grundfragen des modernen Strafrechtssystems, hrsg. v. Schünemann

(1984)

Strafrecht, Allgemeiner Teil, 9. Aufl. (2004); Besonderer Teil II, 8. Aufl. (2005)

Strafrecht, Besonderer Teil I, 9. Aufl. (2009)

s. Ebert 
Hefendehl

Hefendehl Kollektive

Rechtsgüter

Heghmanns BT

Heinrich

vHH

v. Heintschel-Heinegg

v. Hippel I, II

HK-GS

Hohmann/Sander

Hruschka

Jäger BT

Jakobs AT

Jescheck, Beiträge I, II

Jescheck/Weigend

Joecks/Jäger

Kienapfel AT

Kienapfel/Höpfel/Kert

Kienapfel, Urkunden

Kindhäuser AT, BT I, II

Kindhäuser/Böse

Kindhäuser LPK

Kindhäuser, Gefährdung

Kindhäuser/Neumann/

Paeffgen

Klesczewski AT, BT I/II/III

Klesczewski BT

Köhler AT

Kohlrausch/Lange

Krey/Esser

Krey/Hellmann/Heinrich BT 1, 2 Strafrecht, Besonderer Teil, Bd. 1: Besonderer Teil ohne Vermögensdelikte, 16. Aufl. (2015); Bd. 2: Vermögensdelikte, 17. Aufl. (2015)

Kühl AT

Küper/Zopfs BT

Küpper/Börner

Lackner/Kühl

Leipold/Tsambikakis/Zöller

v. Liszt, Aufsätze

v. Liszt/Schmidt AT, BT

Empirische Erkenntnisse, dogmatische Fundamente und kriminalpolitischer Impetus. Symposium für Bernd Schünemann zum 60. Geburtstag, hrsg. v. Hefendehl (2005)

Kollektive Rechtsgüter im Strafrecht (2002)

Strafrecht für alle Semester, Besonderer Teil (2009)

Strafrecht AT, 6. Aufl. (2019)

Strafgesetzbuch, Kommentar, hrsg. v. von Heintschel-Heinegg, 3. Aufl.

(2018)

s. vHH

Deutsches Strafrecht, Bd. 1 (1925), Bd. 2 (1930)

Dölling/Duttge/König/Rössner, Gesamtes Strafrecht, Handkommentar, 4. Aufl. (2017)

Strafrecht Besonderer Teil. BT I: Vermögensdelikte, 3. Aufl. (2011); BT II:

Delikte gegen die Person und gegen die Allgemeinheit, 2. Aufl. (2011)

Strafrecht nach logisch-analytischer Methode, 2. Aufl. (1988)

Examens-Repetitorium Strafrecht Besonderer Teil, 9. Aufl. (2019)

Strafrecht, Allgemeiner Teil, 2. Aufl. (1993)

Strafrecht im Dienste der Gemeinschaft: ausgewählte Beiträge zur Strafrechtsreform, zur Strafrechtsvergleichung, zum internationalen Strafrecht, 1953-1979 (1980) (I); Beiträge zum Strafrecht 1980-1998 (1998) (II), jew.

hrsg. v. Vogler

Lehrbuch des Strafrechts, Allgemeiner Teil, 5. Aufl. (1996)

Strafgesetzbuch, Studienkommentar, 12. Aufl. (2018) (vormals Joecks)

Strafrecht, Allgemeiner Teil, 4. Aufl. (1984)

Strafrecht, Allgemeiner Teil, 15. Aufl. (2016)

Urkunden und andere Gewährschaftsträger im Strafrecht (1967)

Strafrecht, Allgemeiner Teil, 8. Aufl. (2017); Besonderer Teil I:

Straftaten gegen Persönlichkeitsrechte, Staat und Gesellschaft,

8. Aufl. (2017); Besonderer Teil II: Straftaten gegen Vermögensrechte,

9. Aufl. (2016)

Besonderer Teil II: Straftaten gegen Vermögensrechte, 10. Aufl. (2019)

Strafgesetzbuch, Lehr- und Praxiskommentar, 7. Aufl. (2017)

Gefährdung als Straftat (1989)

s. NK

Strafrecht, Allgemeiner Teil (2017); Besonderer Teil I: Straftaten gegen die

Person (2010); Besonderer Teil II: Vermögensdelikte (2011); Besonderer

Teil III: Straftaten gegen Kollektivrechtsgüter (2012)

Strafrecht Besonderer Teil - Lehrbuch zum Strafrecht der Bundesrepublik

Deutschland (2016)

Deutsches Strafrecht, Allgemeiner Teil (1997)

Strafgesetzbuch mit Erläuterungen und Nebengesetzen, 43. Aufl. (1961)

Strafrecht, Allgemeiner Teil, 8. Aufl. (2017)

Strafrecht, Besonderer Teil, 10. Aufl. (2018)

Strafrecht, Besonderer Teil, Bd. 1: Delikte gegen Rechtsgüter der Person

und Gemeinschaft, 4. Aufl. (2017) (vormals Küpper BT)

Strafgesetzbuch mit Erläuterungen, 29. Aufl. (2018)

s. AnwK

Strafrechtliche Aufsätze und Vorträge, 2 Bde. (1925)

Lehrbuch des deutschen Strafrechts, Allgemeiner Teil, 26. Aufl. (1932);

Besonderer Teil, 25. Aufl. (1925) 
LK

Lutz

Madrid-Symposium

Manoledakis/Prittwitz

Matheus

Matt/Renzikowski

Maurach AT, BT

Maurach/Zipf/Jäger

Maurach/Gössel/Zipf

Maurach/Schroeder/

Maiwald I, II

Maurach/Schroeder/

Maiwald/Hoyer/Momsen

H. Mayer AT

H. Mayer, Strafrecht

H. Mayer, Studienbuch

Mezger, Strafrecht

Mitsch BT

MK

Naucke

Niederschriften I-XIV

Niethammer

Niggli/Queloz

NK

Oehler

v. Olshausen

Otto AT, BT

Pfeiffer/Maul/Schulte

Preisendanz

Puppe

Rengier AT, BT 1, 2

Riklin-Hurtado-Symposium

Rostock-Symposium

Roxin AT I, II

Roxin TuT
Strafgesetzbuch, Leipziger Kommentar, 12. Aufl. hrsg. v. Laufhütte/ Rissing-van Saan/Tiedemann (2006ff); 13. Aufl. hrsg. v. Cirener/Radtke/ Rissing-van Saan/Rönnau/Schluckebier (2019 ff)

Strafrecht AT, 14. Aufl. (2019)

s. Schünemann/Suárez

Strafrechtsprobleme an der Jahrtausendwende: Deutsch-Griechisches Symposium in Rostock 1999, hrsg. v. Manoledakis/Prittwitz (2000)

Strafrecht BT 2, 11 Aufl. (2019)

Strafgesetzbuch, Kommentar (2013)

Strafrecht, Allgemeiner Teil, 4. Aufl. (1971); Besonderer Teil, 5. Aufl. (1969)

mit Nachträgen von 1970/71

Strafrecht, Allgemeiner Teil, Teilbd. 1: Grundlehren des Strafrechts und

Aufbau der Straftat, 9. Aufl. (2020)

Strafrecht, Allgemeiner Teil, Teilbd. 2: Erscheinungsformen des Verbrechens und Rechtsfolgen der Tat, 8. Aufl. (2014)

Strafrecht, Besonderer Teil, Teilbd. 1: Straftaten gegen Persönlichkeits- und Vermögenswerte, 10. Aufl. (2009); Teilbd. 2: Straftaten gegen Gemeinschaftswerte, 10. Aufl. (2013)

Strafrecht, Besonderer Teil, Teilbd. 1: Straftaten gegen Persönlichkeits- und Vermögenswerte, 11. Aufl. (2019)

Strafrecht, Allgemeiner Teil (1953)

Das Strafrecht des deutschen Volkes (1936)

Strafrecht, Allgemeiner Teil, Studienbuch (1967)

Strafrecht, Lehrbuch, 3. Aufl. (1949) (ergänzt durch: Moderne Wege der Strafrechtsdogmatik [1950])

Strafrecht, Besonderer Teil, Bd. 2: Vermögensdelikte 3. Aufl. (2015)

Münchener Kommentar zum Strafgesetzbuch, hrsg. von Joecks/Miebach,

2. Aufl. (2011-2015)

Strafrecht, Eine Einführung, 11. Aufl. (2008)

Niederschriften über die Sitzungen der Großen Strafrechtskommission, 14 Bde. (1956-1960)

Lehrbuch des Besonderen Teils des Strafrechts (1950)

Strafjustiz und Rechtsstaat: Symposium zum 60. Geburtstag von Franz

Riklin und José Hurtado Pozo, hrsg. v. Niggli/Queloz (2003)

Nomos-Kommentar zum Strafgesetzbuch, hrsg. von Kindhäuser/Neumann/ Paeffgen, 5. Aufl. (2017)

Internationales Strafrecht, 2. Aufl. (1983)

Kommentar zum Strafgesetzbuch für das Deutsche Reich, 12. Aufl.

(§§ 1-246) bearb. von Freiesleben u.a. (1942 ff); sonst 11. Aufl. bearb. von Lorenz u.a. (1927)

Grundkurs Strafrecht: Allgemeine Strafrechtslehre/Die einzelnen Delikte, jeweils 7. Aufl. (2005)

Strafgesetzbuch, Kommentar an Hand der Rechtsprechung des Bundesgerichtshofes (1969)

Strafgesetzbuch, Lehrkommentar, 30. Aufl. (1978)

Strafrecht Allgemeiner Teil, 4. Aufl. (2019)

Strafrecht, Allgemeiner Teil, 10. Aufl. (2018); Besonderer Teil, Bd. 1:

Vermögensdelikte, 21. Aufl. (2019); Bd. 2: Delikte gegen die Person und die Allgemeinheit, 20. Aufl. (2019)

s. Niggli/Queloz

s. Manoledakis/Prittwitz

Strafrecht, Allgemeiner Teil, Bd. 1: Grundlagen - Der Aufbau der Verbrechenslehre, 4. Aufl. (2006); Strafrecht, Allgemeiner Teil, Bd. 2: Besondere

Erscheinungsformen der Straftat (2003)

Täterschaft und Tatherrschaft, 10. Aufl. (2019) 
Roxin/Stree/Zipf/Jung

Roxin-Symposium

Sack

Safferling

Satzger/Schluckebier/

Widmaier

Sauer AT, BT

Schäfer/v. Dohnanyi

Schmidt AT, BT I, II

Schmidt-Salzer

Schmidhäuser

Schmidhäuser AT, BT, StuB

Schöch

Schönke/Schröder

Schramm

Schroth BT

Schünemann/

de Figueiredo Dias Roxin

Schünemann/Suárez

Sieber

Sieber/Cornils

SK

SLSK

Sonnen

SSW

Stratenwerth/Kuhlen AT

Tendenzen der Kriminalpol

Tiedemann

Tiedemann, Anfängerübung

Tiedemann,

Tatbestandsfunktionen

Tiedemann-Symposium

Walter

v. Weber

Welzel, Strafrecht

Welzel, Strafrechtssystem

Wessels/Beulke/Satzger

Wessels/Hettinger/Engländer

Wessels/Hillenkamp/Schuhr
Einführung in das neue Strafrecht, 2. Aufl. (1975)

s. Gimbernat

Umweltschutz-Strafrecht, Erläuterung der Straf- und Bußgeldvorschriften, Loseblattausgabe, 43. Aufl. (2018)

Internationales Strafrecht (2011)

s. SSW

Allgemeine Strafrechtslehre, 3. Aufl. (1955); System des Strafrechts, Besonderer Teil (1954)

Die Strafgesetzgebung der Jahre 1931 bis 1935 (1936) (Nachtrag zur 18. Aufl. von Frank: das Strafgesetzbuch für das Deutsche Reich [1931])

Strafrecht, Allgemeiner Teil, 20. Aufl. (2018); Besonderer Teil I und II jeweils 20. Aufl. (2018)

Produkthaftung, Bd. 1: Strafrecht, 2. Aufl. (1988)

Einführung in das Strafrecht, 2. Aufl. (1984)

Strafrecht, Allgemeiner Teil, 2. Aufl. (1975); Besonderer Teil, 2. Aufl. (1983);

Studienbuch: Allgemeiner Teil, 2. Aufl. (1984)

Wiedergutmachung und Strafrecht: Symposium aus Anlaß des 80. Geburtstages von Friedrich Schaffstein, hrsg. v. Schöch (1987)

Strafgesetzbuch, Kommentar, 30. Aufl. (2019)

Internationales Strafrecht (2011)

Strafrecht, Besonderer Teil, 5. Aufl. (2010)

Bausteine des Europäischen Strafrechts: Coimbra-Symposium für Claus, hrsg. v. Schünemann/de Figueiredo Dias (1995)

Bausteine des europäischen Wirtschaftsstrafrechts: Madrid-Symposium für Klaus Tiedemann, hrsg. v. Schünemann/Suárez (1994)

Verantwortlichkeit im Internet (1999)

Nationales Strafrecht in rechtsvergleichender Darstellung, hrsg. von Sieber/Cornils (2008 ff)

Systematischer Kommentar zum Strafgesetzbuch, 9. Aufl. (2017)

Systematischer Leitsatzkommentar zum Sanktionenrecht, hrsg. v. Horn,

Loseblattausgabe (1983 ff)

Strafrecht Besonderer Teil (2005)

Strafgesetzbuch, Kommentar, hrsg. v. Satzger/Schluckebier/Widmaier, 4. Aufl. (2019)

Strafrecht, Allgemeiner Teil - Die Straftat, 6. Aufl. (2011)

k Neuere Tendenzen der Kriminalpolitik, Beiträge zu einem deutsch-

skandinavischen Strafrechtskolloquium, hrsg. v. Cornils/Eser (1987)

Wirtschaftsstrafrecht in der Europäischen Union, Rechtsdogmatik Rechtsvergleich - Rechtspolitik (Freiburg-Syposium), hrsg. v. Tiedemann (2002)

Die Anfängerübung im Strafrecht, 4. Aufl. (1999)

Tatbestandsfunktionen im Nebenstrafrecht (1969)

s. Schünemann/Suárez

Der Kern des Strafrechts (2006)

Grundriß des deutschen Strafrechts, 2. Aufl. (1948)

Das Deutsche Strafrecht, 11. Aufl. (1969)

Das neue Bild des Strafrechtssystems, 4. Aufl. (1961)

Strafrecht, Allgemeiner Teil, 48. Aufl. (2018)

Strafrecht, Besonderer Teil 1: Straftaten gegen Persönlichkeits- und Gemeinschaftswerte, 42. Aufl. (2018)

Strafrecht, Besonderer Teil 2: Straftaten gegen Vermögenswerte, 419. Aufl.

(2018) 
WK

Wohlers Deliktstypen

Wolters

Zieschang AT

Zieschang, Gefährdungs-

delikte
Wiener Kommentar zum Strafgesetzbuch - StGB; hrsg. v. Höpfl/Ratz, Loseblatt, 2. Aufl. (1999 ff)

Deliktstypen des Präventionsrechts - Zur Dogmatik „moderner“ Gefährdungsdelikte (2000)

Das Unternehmensdelikt (2001)

Strafrecht, Allgemeiner Teil, 5. Aufl. (2017)

Die Gefährdungsdelikte (1998)

\section{Betäubungsmittelstrafrecht}

Franke/Wienroeder

Joachimski/Haumer

Körner/Patzak/Volkmer

Webel

Weber
Betäubungsmittelgesetz, Kommentar, 5. Aufl. (2017)

Betäubungsmittelgesetz (mit ergänzenden Bestimmungen), Kommentar, 7. Aufl. (2002)

Betäubungsmittelgesetz, Kurzkommentar, 9. Aufl. (2019)

Betäubungsmittelstrafrecht (2003)

Betäubungsmittelgesetz, Kommentar, 4. Aufl. (2013); 5. Aufl. (2017)

\section{Bürgerliches Recht einschließlich Versicherungsrecht}

Bruck/Möller
Erman
Jauernig
Larenz/Wolf
MK-BGB

MK-VVG

Palandt

Prütting/Wegen/Weinreich RGRK

HK-BGB

Soergel

Staudinger

Wolf/Neuner

\section{DDR-Strafrecht}

StGB-Komm.-DDR

StGB-Lehrb.-DDR AT, BT
Großkommentar zum Versicherungsvertragsgesetz, 9. Aufl. (2008ff)

Handkommentar zum Bürgerlichen Gesetzbuch, 15. Aufl. (2017)

Bürgerliches Gesetzbuch: BGB, 17. Aufl. (2018)

s. Wolf/Neuner

Münchener Kommentar zum Bürgerlichen Gesetzbuch, 6. Auflage (ab 2011), hrsg. v. Säcker/Rixecker/Oetker; 7. Aufl. (ab 2015), hrsg. von Säcker/Rixecker/Oetker/Limperg; 8. Aufl. (ab 2018), hrsg. von Säcker/Rixecker/Oetker/Limperg

Münchener Kommentar zum Versicherungsvertragsgesetz, hrsg. v. Langheid/Wandt (2009); 2. Aufl. (2016)

Bürgerliches Gesetzbuch mit Einführungsgesetz (Auszug), Gesetz zur Regelung des Rechts der Allgemeinen Geschäftsbedingungen, Verbraucherkreditgesetz, Gesetz über den Widerruf von Haustürgeschäften und ähnlichen Geschäften, Kurzkommentar, 78. Aufl. (2019)

BGB Kommentar, 14. Aufl. (2019)

Das Bürgerliche Gesetzbuch, Kommentar, mit besonderer Berücksichtigung der Rechtsprechung des Reichsgerichts und des Bundesgerichtshofes (Reichsgerichtsrätekommentar), hrsg. v. Mitgliedern des Bundesgerichtshofes, 12. Aufl. (1975-1999)

Schul-

ze/Dörner/Ebert/Hoeren/Kemper/Saenger/Scheuch/Schreiber/SchulteNölke/Staudinger/Wiese, Bürgerliches Gesetzbuch, Handkommentar, 10. Aufl. (2019)

Bürgerliches Gesetzbuch mit Einführungsgesetz und Nebengesetzen, 13. Aufl. (1999 ff)

J. von Staudingers Kommentar zum Bürgerlichen Gesetzbuch mit Einführungsgesetz und Nebengesetzen, 13. Aufl. Bearbeitungen (1993ff)

Allgemeiner Teil des Bürgerlichen Rechts, 10. Aufl. (2012); 11. Aufl. (2016)

Strafrecht der Deutschen Demokratischen Republik, Kommentar, 5. Aufl. (1987)

Strafrecht der DDR, Lehrbuch: Allgemeiner Teil, 2. Aufl. (1976); Besonderer Teil (1981) 
StGB-Lehrb.-DDR 1988

StPO-Komm.-DDR

StPO-Lehrb.-DDR

\section{Europäisches Recht}

Bleckmann
Geiger/Khan/Kotzur
GKK
GKN
Grabitz/Hilf/Nettesheim
Hailbronner/Klein/Magiera/
Müller-Graff
HKMM

HdEuropR

Hecker

Hobe

IM EG

Immenga/Mestmäcker EG

Satzger

Schwarze/Becker/Hatje/Schoo

Schweitzer/Hummer

Sieber/Satzger/

v.Heintschel-Heinegg

SSvHH

Streinz
Strafrecht der DDR, Lehrbuch, Allgemeiner Teil (1988)

Strafprozeßrecht der Deutschen Demokratischen Republik, Kommentar, 3. Aufl. (1989)

Strafverfahrensrecht, Lehrbuch, 3. Aufl. (1987)

Europarecht, 6. Aufl. (1997)

s. GKK

EUV/AEUV, Kommentar, hrsg. v. Geiger/Khan/Kotzur, 6. Aufl. (2017)

Das Recht der Europäischen Union, Kommentar, Loseblattausgabe,

hrsg. v. Grabitz/Hilf/Nettesheim, 66. Aufl. (2019)

s. GKN

\section{s. HKMM}

Handkommentar zum Vertrag über die Europäische Union (EUV/EGV), hrsg. v. Hailbronner/Klein/Magiera/Müller-Graff, Loseblattausgabe (1991ff)

Handbuch des Europäischen Rechts, Loseblattausgabe, hrsg. v. Bieber/Ehlermann (1982 ff)

Europäisches Strafrecht, 5. Aufl. (2015)

Europarecht, 9. Aufl. (2017)

Wettbewerbsrecht: Band 1. EU, 2 Teilbände., hrsg. v. Immenga/Mestmäcker, 6. Aufl. (2019)

s. IM EG

Internationales und Europäisches Strafrecht, 8. Aufl. (2018)

EU-Kommentar, hrsg. v. Schwarze/Becker/Hatje/Schoo, 4. Aufl. (2019)

(vormals Schwarze)

Europarecht, 6. Aufl. (2008)

s. SSvHH

Europäisches Strafrecht, hrsg. v. Sieber/Satzger/v.Heintschel-Heinegg, 2. Aufl. (2014)

Europarecht, 10. Aufl. (2016)

\section{Handelsrecht einschließlich Bilanz- und Gesellschaftsrecht}

Baumbach/Hopt

Ebenroth/Boujong/Joost/

Strohn

Großfeld/Luttermann

Hachenburg

Heymann

GK-AktG

Hüffer/Koch

MK HGB

Schmidt/Lutter

Scholz

Staub

Ulmer/Habersack/Löbbe

UHL
Handelsgesetzbuch: HGB mit GmbH \& Co., Handelsklauseln, Bank- und Börsenrecht, Transportrecht, 38. Aufl. (2018)

Handelsgesetzbuch, 4. Aufl. (2019/20)

Bilanzrecht, 5. Aufl. (2009)

GmbHG, Kommentar, 8. Aufl. (1993 bis 1997)

HGB, Kommentar, 3. Aufl. (2019/20)

Großkommentar zum Aktiengesetz, 4. Aufl. hrsg. v. Hopt/Wiedemann (1992ff); 5. Aufl. hrsg. v. Hirte/Mülbert/Roth (2015ff)

Aktiengesetz: AktG, Kommentar, 13. Aufl. (2018) (vormals Hüffer)

Münchener Kommentar zum Handelsgesetzbuch, hrsg. v. K. Schmidt, 3. Aufl. (2010 ff); 4. Aufl. (2016ff)

AktG Kommentar in 2 Bänden, 3. Aufl. (2015)

Kommentar zum GmbH-Gesetz in 3 Bänden, 11. Aufl. (2012ff)

Großkommentar zum HGB, 5. Aufl. (2008ff)

s. UHL

GmbHG Großkommentar in 2 Bänden, 2. Aufl. hrsg. v. Ulmer/Habersack/ Löbbe (2016) 


\title{
7. Jugendstrafrecht
}

\author{
AK JGG \\ Brunner \\ Brunner/Dölling \\ Böhm/Feuerhelm \\ Diemer/Schatz/Sonnen \\ Eisenberg JGG \\ Laubenthal/Baier/Nestler \\ Kommentar zum Jugendgerichtsgesetz - Reihe Alternativkommentare, \\ hrsg. v. Wassermann (1987) \\ Jugendgerichtsgesetz, Kommentar, 9. Aufl. (1991) \\ Jugendgerichtsgesetz, Kommentar, 13. Aufl. (2017) \\ Einführung in das Jugendstrafrecht, 4. Aufl. (2004) \\ Jugendgerichtsgesetz mit Jugendstrafvollzugsgesetzen, Kommentar, \\ 7. Aufl. (2015) \\ Jugendgerichtsgesetz, Kommentar, 20. Aufl. (2018) \\ Jugendstrafrecht, 3. Aufl. (2015) \\ Ostendorf JGG \\ Jugendgerichtsgesetz, Kommentar, 10. Aufl. (2016) \\ Schaffstein/Beulke/Swoboda \\ Streng \\ Walter/Neubacher \\ Jugendstrafrecht, 15. Aufl. (2015) \\ Jugendstrafrecht, 4. Aufl. (2016) \\ Jugendkriminalität: eine systematische Darstellung, 4. Aufl. (2011)
}

\section{Kriminologie}

Albrecht

Dittmann/Jehle

Eisenberg, Kriminologie

Göppinger

Göppinger/Bock

HwbKrim

IntHdbKrim

Kaiser/Schöch/Kinzig

Kaiser, Einführung

Meier

Mezger, Kriminologie

Schneider

Schwind

Kriminologie, 4. Aufl. (2010)

Kriminologie zwischen Grundlagenwissenschaften und Praxis, hrsg. v. Dittmann/Jehle (2003)

Kriminologie, 7. Aufl. (2017)

Kriminologie, 4. Aufl. (1980)

Kriminologie, 6. Aufl. hrsg. v. Göppinger/Bock/Kröber et.al. (2008)

Handwörterbuch der Kriminologie, hrsg. v. Sieverts/Schneider, Bd. 1-3, Ergänzungsband (4. Bd.), Nachtrags- und Registerband (5. Bd.), 2. Aufl. (1966-1998)

Internationales Handbuch der Kriminologie, hrsg. v. H.-J. Schneider, Bd 1 (2007); Bd 2 (2009)

Kriminologie, Jugendstrafrecht und Strafvollzug, 8. Aufl. hrsg. v.

Schöch/Kinzig (2015)

Kriminologie: eine Einführung in die Grundlagen, 10. Aufl. (1997)

Kriminologie, 5. Aufl. (2016)

Kriminologie, Studienbuch (1951)

Kriminologie, Lehrbuch, 3. Aufl. (1992)

Kriminologie und Kriminalpolitik, 23. Aufl. (2016)

\section{Ordnungswidrigkeitenrecht}

Bohnert/Krenberger/Krumm

Bohnert/Bülte

Göhler

HK-OWiG

KK-OWiG

Krenberger/Krumm

Mitsch, OWiG

Rebmann/Roth/Hermann s. Krenberger/Krumm

Ordnungswidrigkeitenrecht, Grundriss für Praxis und Ausbildung, 5. Aufl. (2016) (vormals Bohnert)

Gesetz über Ordnungswidrigkeiten, Kurzkommentar, 17. Aufl. (2017)

Heidelberger Kommentar zum Ordnungswidrigkeitengesetz, hrsg. v. Lemke u.a., 2. Aufl. (2005)

Karlsruher Kommentar zum Gesetz über Ordnungswidrigkeiten, hrsg. v. Senge, 5. Aufl. (2018)

OWiG Ordnungswidrigkeitengesetz, Kommentar, 5. Aufl. (2018) (vormals

Bohnert/Krenberger/Krumm)

Recht der Ordnungswidrigkeiten, 2. Aufl. (2005)

Gesetz über Ordnungswidrigkeiten, Kommentar, Loseblattausgabe (2002ff) 


\section{Presserecht}

Groß

Löffler

Löffler HdB

Ricker/Weberling

Soehring/Hoene

\section{Rechtshilfe}

Grützner/Pötz/Kreß

Hackner/Lagodny/

Schomburg/Wolf

Schomburg/Lagodny/

Gleß/Hackner

Vogler/Wilkitzki
Presserecht, 3. Aufl. (1999)

Presserecht, Kommentar, 6. Aufl. (2015)

s. Ricker/Weberling

Handbuch des Presserechts, begr. v. Löffler, hrsg. v. Ricker/Weberling, 6. Aufl. (2012)

Presserecht, 6. Aufl. (2019) (vormals Soehring)

Internationaler Rechtshilfeverkehr in Strafsachen, Loseblattausgabe, 39. Aktualisierung, 2016

Internationale Rechtshilfe in Strafsachen (2003)

Internationale Rechtshilfe in Strafsachen, 6. Aufl. (2019)

Gesetz über die Internationale Rechtshilfe in Strafsachen (IRG), Kommentar, Loseblattausgabe (1992 ff) als Sonderausgabe aus Grützner/Pötz, Internationaler Rechtshilfeverkehr in Strafsachen, 2. Aufl. (1980 ff)

\section{Rechtsmedizin und Medizinstrafrecht}

Foerster/Dreßing

Forster

Forster/Ropohl

Frister/Lindemann/Peters

HfPsych I, II

Laufs

Laufs/Katzenmeier/Lipp

Laufs/Kern

Rieger

Roxin/Schroth

Spickhoff

Ulsenheimer

Wenzel
Psychiatrische Begutachtung, hrsg. v. Venzlaff/Foerster/Dreßing/

Habermeyer, 6. Aufl. (2015)

Praxis der Rechtsmedizin (1986)

Rechtsmedizin, 5. Aufl. (1989)

Arztstrafrecht (2011)

Handbuch der forensischen Psychiatrie, hrsg. v. Kröber/Dölling/Leygraf/ Saß, Bd. 1: Strafrechtliche Grundlagen der Gutachtenerstellung im Strafverfahren (2007); Bd. 2: Psychopathologische Grundlagen und Praxis der forensischen Psychiatrie im Strafrecht (2011); Bd. 3: Psychiatrische Kriminalprognose und Kriminaltherapie (2006); Bd. 4: Kriminologie und forensische Psychiatrie (2009); Bd. 5: Forensische Psychiatrie im Privatrecht und Öffentlichen Recht (2009)

Fortpflanzungsmedizin und Arztrecht (1992)

Arztrecht, hrsg. v. Katzenmeier/Lipp, 7. Aufl. (2015)

Handbuch des Arztrechts, hrsg. v. Laufs/Kern, 5. Aufl. (2019)

Lexikon des Arztrechts, hrsg. v. Rieger/Dahm/Steinhilper Loseblatt (2004) Handbuch des Medizinstrafrechts, hrsg. v. Roxin/Schroth, 4. Aufl. (2010) Medizinrecht, hrsg. v. Spickhoff, 3. Aufl. (2018)

Arztstrafrecht in der Praxis, 5. Aufl. (2015)

Medizinrecht, hrsg. v. Wenzel, 4. Aufl. (2019)

\section{Strafprozess- und Strafvollzugsrecht}

\section{AK-StPO}

AK-StVollzG

Arloth/Krä

BeckOK-StPO

Beulke/Swoboda

Bringewat
Kommentar zur Strafprozeßordnung - Reihe Alternativkommentare, hrsg. v. Wassermann, Bd. 1 (1988), Bd. 2 Teilbd. 1 (1992), Bd. 2 Teilbd. 2 (1993), Bd. 3 (1996)

Kommentar zum Strafvollzugsgesetz - Reihe Alternativkommentare, hrsg. v. Wassermann, 3. Aufl. (1990)

Strafvollzugsgesetze, Kommentar, 4. Aufl. (2017)

Beck'scher Online-Kommentar StPO, hrsg. v. Graf, 33. Edition (2019)

Strafprozessrecht, 14. Aufl. (2018) (vormals Beulke)

Strafvollstreckungsrecht: Kommentar zu den §§ 449-463d StPO (1993) 


Calliess/Müller-Dietz
Eisenberg
Hamm
HK-StPO
Isak/Wagner
Joecks-StPO
Kamann
Kammeier/Pollähne
Kissel/Mayer
KK
Kleinknecht/Meyer-Goßner
KMR

Kramer

Kühne

Laubenthal/Nestler/

Neubacher/Verrel

LNNV

LR

Marschner/Lesting/Stahmann

Meyer-Goßner/Schmitt

Müller

Peters

Pfeiffer

Pohlmann/Jabel/Wolf

Putzke/Scheinfeld

Röttle/Wagner

Roxin/Schünemann

Roxin/Arzt/Tiedemann

Saage/Göppinger

Sarstedt/Hamm

Satzger/Schluckebier/

Widmaier

Schäfer, Strafverfahren

Schäfer/Sander/

van Gemmeren

Schätzler

Eb. Schmidt,

Lehrkommentar I-III

Schwind/Böhm/

Jehle/Laubenthal s. Laubenthal/Nestler/Neubacher/Verrel

Beweisrecht der StPO, Spezialkommentar, 10. Aufl. (2017)

Die Revision in Strafsachen, 7. Aufl. (2010)

Heidelberger Kommentar zur Strafprozessordnung, hrsg. v. Gercke u.a.,

6. Aufl. (2019)

s. Röttle/Wagner

Studienkommentar StPO, hrsg. v. Joecks/Jäger 5. Aufl. (2019)

Handbuch für die Strafvollstreckung und den Strafvollzug, 2. Aufl. (2008)

Maßregelvollzugsrecht, Kommentar, 4. Aufl. (2018)

Gerichtsverfassungsgesetz, 9. Aufl. (2018)

Karlsruher Kommentar, Strafprozessordnung - GVG, EGGVG, EMRK, hrsg.

v. Hannich, 8. Aufl. (2019)

s. Meyer-Goßner/Schmitt

Kleinknecht/Müller/Reitberger (Begr.), Kommentar zur Strafprozeß-

ordnung, Loseblattausgabe, 8. Aufl. (1990 ff), ab 14. Lfg. hrsg. von v.

Heintschel-Heinegg/Stöckel

Grundlagen des Strafverfahrensrechts: Ermittlung und Verfahren, 8. Aufl. (2014)

Strafprozessrecht (ehem. Strafprozeßlehre) 9. Aufl. (2015)

\section{s. LNNV}

Strafvollzugsgesetz, Kurzkommentar, hrsg. v. Laubenthal/Nestler/

Neubacher/Verrel begr. und bis zur 11. Aufl. fortgeführt von Callies/MüllerDietz, 12. Aufl. (2015)

Löwe-Rosenberg, Die Strafprozeßordnung und das Gerichtsverfassungsgesetz mitNebengesetzen, Großkommentar, 26.Aufl. (2006 ff), 27. Aufl. (2016ff)

Marschner/Volckart/Lesting; Saage/Göppinger)

Strafprozessordnung mit GVG und Nebengesetzen, Kurzkommentar, 62. Aufl. (2019) vormals Kleinknecht/Meyer-Goßner

Beiträge zum Strafprozessrecht (2003)

Strafprozeß, Ein Lehrbuch, 4. Aufl. (1985)

Strafprozeßordnung und Gerichtsverfassungsgesetz, 6. Aufl. (2008)

Strafvollstreckungsordnung, Kommentar, 9. Aufl. (2015)

Strafprozessrecht, 7. Aufl. (2017)

Strafvollstreckung, 8. Aufl. (2009); (vormals Wetterich/Hamann; Isak/

Wagner)

Strafverfahrensrecht, 29. Aufl. (2017)

Strafrecht und Strafprozessrecht, 6. Auflage (2014)

s. Marschner/Volckart

s. Hamm

s. SSW-StPO

Die Praxis des Strafverfahrens, 6. Aufl. (2000), 7. Aufl. (2018)

Die Praxis der Strafzumessung, 6. Aufl. (2017)

Handbuch des Gnadenrechts, 2. Aufl. (1992)

Strafprozeßordnung, Lehrkommentar, Bd. 1: Die rechtstheoretischen und die rechtspolitischen Grundlagen des Strafverfahrensrechts, 2. Aufl. (1964); Bd. 2: Erläuterungen zur Strafprozeßordnung und zum Einführungsgesetz zur Strafprozeßordnung (1957) (mit Nachtragsband 1 [1967] und 2 [1970]); Bd. 3: Erläuterungen zum Gerichtsverfassungsgesetz und zum Einführungsgesetz zum Gerichtsverfassungsgesetz (1960)

Strafvollzugsgesetz, Kommentar, 7. Auflage (2019) 
SK-StPO

\section{SSW-StPO}

Ulrich

Volckart/Grünebaum

Volk/Engländer

Walter, Strafvollzug

\section{Straßenverkehrsrecht}

Bär/Hauser/Lehmpuhl

Beck/Berr/Schäpe

Berz/Burmann

Burmann/Heß u.a.

Cramer
Full/Möhl/Rüth
Haus/Krumm/Quarch
Hentschel
Hentschel/Born
Hentschel/König/Dauer
Hentschel/Krumm
Himmelreich/Hentschel
Himmelreich/Staub/
Krumm/Nissen
HKD

HK-StVR

Janker Jagow/Burmann/Heß Jagusch/Hentschel Janiszewski Janiszewski/Jagow/Burmann JBH

MK-StVR

Müller I-III

Rüth/Berr/Berz
Systematischer Kommentar zur Strafprozessordnung mit GVG und EMRK, hrsg. v. Wolter, Loseblattausgabe (1986 ff, 5. Aufl. 2016 ff) Strafprozessordnung, Kommentar, hrsg. v. Satzger/Schluckebier/ Widmaier, 3. Aufl. (2018)

Der gerichtliche Sachverständige, 13. Aufl. (2017), ehem. Jessnitzer/Ulrich Maßregelvollzug, 8. Aufl. (2015)

Grundkurs StPO, 9. Aufl. (2018)

Strafvollzug, 2. Aufl. (1999)

Unfallflucht, Kommentar, Loseblattausgabe (1978 ff)

OWi - Sachen im Straßenverkehrsrecht, 7. Aufl. (2017) (vormals Beck/ Berr)

Handbuch des Straßenverkehrsrechts, hrsg. von Burmann/Heß, Loseblattausgabe, 39. Erg.-Lfg. (2019)

Straßenverkehrsrecht, Kommentar, 25. Aufl. (2018), hrsg. v. Burmann/ Heß/Hühnermann/Jahnke (vormals Burmann/Heß/Hühnermann/Jahnke/ Janker; Jagow/Burmann/Heß)

Straßenverkehrsrecht, Bd. 1: StVO, StGB, 2. Aufl. (1977)

Straßenverkehrsrecht: Kommentar (1980) mit Nachtrag (1980/81)

Gesamtes Verkehrsrecht, hrsg. von Haus/Krumm/Quarch , 2. Aufl. (2017)

Trunkenheit, Fahrerlaubnisentziehung, Fahrverbot im Straf- und Ordnungswidrigkeitenrecht, 10. Aufl. (2006)

Trunkenheit im Straßenverkehr, 7. Aufl. (1996)

s. HKD

Fahrerlaubnis - Alkohol - Drogen im Straf- und Ordnungswidrigkeitenrecht, 7. Aufl. (2018)

Fahrverbot, Führerscheinentzug; Bd. 1: Straf- und Ordnungswidrigkeitenrecht, 8. Aufl. (1995)

Verkehrsunfallflucht: Verteidigerstrategien im Rahmen des $\S 142$ StGB, 7. Aufl. (2019) (vormals Himmelreich/Bücken/Krumm)

Straßenverkehrsrecht, hrsg. v. Hentschel/König/Dauer, 45. Aufl. (2019) vormals Jagusch/Hentschel

Heidelberger Kommentar zum Straßenverkehrsrecht, hrsg. v. Griesbaum u.a. (1993)

Straßenverkehrsdelikte: Ansatzpunkte für die Verteidigung (2002)

s. JBH

s. HKD

Verkehrsstrafrecht, 5. Aufl. (2004)

s. JBH

Straßenverkehrsrecht, Kommentar, hrsg. v. Jagow/Burmann/Heß, vormals Janiszewski/Jagow/Burmann; 20. Aufl. (2008)

Münchener Kommentar zum Straßenverkehrsrecht, hrsg. von Bender/König (2016ff)

Straßenverkehrsrecht, Großkommentar, 22. Aufl., Bd. 1 (1969) mit Nachtrag 1969, Bd. 2 (1969), Bd. 3 (1973)

Straßenverkehrsrecht, Kommentar, 2. Aufl. (1988)

\section{Verfassungsrecht und Verwaltungsrecht}

AK-GG

Battis

BK
Alternativkommentar Grundgesetz, hrsg. v. Wassermann, 3. Aufl. (2001)

Bundesbeamtengesetz, Kommentar, 5. Aufl. (2017)

Kommentar zum Bonner Grundgesetz (Bonner Kommentar), Loseblattausgabe, hrsg. v. Kahl/Waldhoff/Walter 198. Lfg. (2019) 
Clemens/Scheuring/

Steingen/Wiese

Dreier I-III

Friauf

Fuhr/Stahlhacke

HdStR I-XIII

Jarass/Pieroth

Kopp/Ramsauer

Landmann/Rohmer I, II

v. Mangoldt/Klein/Starck

Maunz/Dürig

Maunz/Schmidt-Bleibtreu/

Klein/Bethge

MSBKB

Klein/Ulsamer

v. Münch/Kunig

Plog/Wiedow

Sachs

Schmidt-Aßmann/Schoch

Schmidt-Bleibtreu/

Hofmann/Henneckef

Stern I-V

TVöD

Wolff/Bachof/Stober/Kluth s. TVöD

Grundgesetz, Kommentar, 3. Aufl., (Bd. 1: 2013; Bd. 2: 2015; Bd. 3: 2017)

Kommentar zur Gewerbeordnung - GewO, Gewerberechtlicher Teil, Lose-

blattausgabe, hrsg. v. Friauf (2001 ff)

s. Friauf

Handbuch des Staatsrechts der Bundesrepublik Deutschland, hrsg.

v. Isensee/Kirchhof, 3. Aufl (Bd. 1: 2003; Bd. 2: 2004; Bd. 3: 2005; Bd. 4: 2006; Bd. 5: 2007; Bd. 6: 2009; Bd. 7: 2009; Bd. 8: 2010; Bd. 9: 2011; Bd. 10: 2012, Bd. 11: 2013, Bd. 12: 2014, Bd. 13: 2015

Grundgesetz für die Bundesrepublik Deutschland: Kommentar, 15. Aufl. (2018)

Verwaltungsverfahrensgesetz, 20. Aufl. (2019)

Gewerbeordnung und ergänzende Vorschriften, Kommentar, Loseblattausgabe, Bd. 1: Gewerbeordnung; Bd. 2: Ergänzende Vorschriften (jew. 1998ff)

Kommentar zum Grundgesetz, Bd. 1 (Art. 1-19), Bd. 2 (Art. 20-82), Bd. 3 (Art. 83-146), 7. Aufl. (2017); früherer Titel: Das Bonner Grundgesetz Grundgesetz, Kommentar, Loseblattausgabe, 7. Aufl. (1991 ff) (bearb.v. Badura u.a.), 86. Aufl. (2019)

s. MSBKB

Bundesverfassungsgerichtsgesetz, Kommentar, Loseblatt, hrsg. v. Maunz/ Schmidt-Bleibtreu/Klein/Bethge, 56. Aufl. (2019)

nunmehr: Maunz/Schmidt-Bleibtreu/Klein/Bethge

Grundgesetz, Kommentar, Gesamtwerk in 2 Bänden, 6. Aufl. (2012)

Kommentar zum Bundesbeamtengesetz, mit Beamtenversorgungsgesetz, 404. Erg.-Lfg. (2019)

Grundgesetz-Kommentar, 8. Auflage (2018)

Besonderes Verwaltungsrecht, 14. Aufl. (2008)

Kommentar zum Grundgesetz, 14. Aufl. (2018)

Das Staatsrecht der Bundesrepublik Deutschland, Bd. 1, 2. Aufl. (1984); Bd. 2 (1980); Bd. 3/1 (1988); Bd. 3/2 (1994); Bd. 4 (1997); Bd. 4/2 (2006); Bd. 5 (2000)

Kommentar zum Tarifvertrag öffentlicher Dienst (TVöD), hrsg. v. Clemens/ Scheuring/Steingen/Wiese, Loseblatt. 110 Erg-Lfg. (2019)

Verwaltungsrecht, Band 1, 13. Aufl. (2017)

\section{Wettbewerbs- und Kartellrecht}

Baumbach/Hefermehl

Dreher/Kulka

Emmerich, Kartellrecht

Emmerich/Lange

FK Kartellrecht [GWB]

Fezer/Büscher/Obergfell

Immenga/Mestmäcker GWB s. Köhler/Bornkamm

Wettbewerbs- und Kartellrecht, 10. Aufl. (2018) (vormals Rittner/ Dreher/Kulka)

Kartellrecht, Studienbuch, 14. Aufl. (2018)

Unlauterer Wettbewerb, 11. Auflage (2019) (vormals Emmerich)

Frankfurter Kommentar zum Kartellrecht, mit Kommentierung des GWB, des EG-Kartellrechts und einer Darstellung ausländischer Kartellrechtsordnungen, Loseblattausgabe, hrsg. v. Glassen u.a. (2001ff) bis zur 44. Lfg. unter dem Titel: Frankfurter Kommentar zum Gesetz gegen Wettbewerbsbeschränkungen

Lauterkeitsrecht (Kommentar zum UWG) 2 Bände, 3. Aufl. (2016) (vormals Fezer)

Wettbewerbsrecht, Kommentar, hrsg. v. Immenga/Mestmäcker, 6. Aufl. (2019) 
Köhler/Bornkamm/Feddersen Gesetz gegen den unlauteren Wettbewerb UWG - mit PAngV, UKlaG, DL-InfoV 37. Aufl. (2019) (vormals Köhler/Bornkamm)

Köhler/Piper

Ohly/Sosnitza

Rittner/Dreher s. Ohly/Sosnitza

UWG - Gesetz gegen den unlauteren Wettbewerb, Kommentar, 7. Aufl. (2016)

Europäisches und deutsches Wirtschaftsrecht, 3. Aufl. (2008)

\section{Wirtschafts- und Steuerstrafrecht}

Achenbach/Ransiek/Rönnau
ARR
Belke/Oehmichen
Bender/Möller/Retemeyer
Bittmann
Brüssow/Petri
Dannecker/Knierim/Smok
Eidam
Franzen/Gast/Joecks
Geilen, Aktienstrafrecht
GJW
Graf/Jäger/Wittig
Greeve/Leipold
Hellmann/Beckemper
Hübschmann/Hepp/Spitaler
HHS

HWiStR

Ignor/Mosbacher Joecks/Jäger/Randt JJR

Kempf/Lüderssen/Volk

Klein

Kohlmann

Kohlmann/Reinhart

Krekeler/Tiedemann/ Ulsenheimer/ Weinmann

Kudlich/Oğlakcığlu Kühn/von Wedelstädt KvW

MG

Müller-Gugenberger Otto, Aktienstrafrecht

\section{s. ARR}

Handbuch Wirtschaftsstrafrecht, hrsg. v. Achenbach/Ransiek/Rönnau, 5. Aufl. (2019)

Wirtschaftskriminalität - aktuelle Fragen des Wirtschaftsstrafrechts in Theorie und Praxis (1983)

Steuerstrafrecht - Mit Schwerpunkt Zoll- und Verbrauchssteuerstrafrecht, Loseblatt 46. Akt. (2019)

Insolvenzstrafrecht, hrsg. von Bittmann, 2. Aufl. (2017)

Arbeitsstrafrecht, 2. Aufl. (2016)

Insolvenzstrafrecht, 3. Aufl. (2018) (vormals Dannecker/Knierim/

Hagemeier)

Unternehmen und Strafe, 5. Aufl. (2018)

s. JJR

Erläuterungen zu §§ 399- 405 AktG von Gerd Geilen, Erläuterungen zu $\S 408$ AktG von Wolfgang Zöllner (1984) (Sonderausgabe aus der 1. Aufl. des Kölner Kommentars zum Aktiengesetz)

Wirtschafts- und Steuerstrafrecht, hrsg. v. Graf/Jäger/Wittig, 2. Aufl. (2017) s. GJW

Handbuch des Baustrafrechts (2004)

Wirtschaftsstrafrecht, 5. Aufl. (2018)

s. HHS

Abgabenordnung, Finanzgerichtsordnung, Kommentar, Loseblattausgabe, (bearb. v. Söhn et al.) 252. Akt. (2019)

Handwörterbuch des Wirtschafts- und Steuerstrafrechts, Loseblattausgabe (1985-1990), hrsg. v. Krekeler/Tiedemann u.a.

Handbuch Arbeitsstrafrecht, 3. Aufl. (2016) (vormals Ignor/Rixen)

Steuerstrafrecht, 9. Aufl. (2019) (vormals Joecks)

Steuerstrafrecht: mit Zoll- und Verbrauchssteuerstrafrecht; Kommentar zu $\S \S 369-412$ AO; § 32 ZollVG, 8. Aufl. (2015)

Die Handlungsfreiheit des Unternehmers, hrsg. v. Kempf/Lüderssen/Volk (2009)

AO - Abgabenordnung, Kommentar, 14. Aufl. (2018)

Steuerstrafrecht, Kommentar zu den $\S \S 369-412$ AO 1977, Loseblatt.

63. Akt. (2019)

Die strafrechtliche Verantwortlichkeit des GmbH-Geschäftsführers, 2. Aufl.

(2019)

Handwörterbuch des Wirtschafts- und Steuerstrafrechts, hrsg. von

Krekeler/Tiedemann/Ulsenheimer/Weinmann (1985-1990)

Wirtschaftsstrafrecht, 2. Aufl. (2014)

s. KvW

Abgabenordnung und Finanzgerichtsordnung, hrsg. v. Kühn/von Wedel-

städt, 22. Aufl. (2018)

Wirtschaftsstrafrecht, hrsg. von Müller-Gugenberger, 6. Aufl. (2015)

s. MG

Erläuterungen zu den $\S \S 399-410$ AktG (1997) (Sonderausgabe aus der

4. Aufl. des Großkommentars zum Aktiengesetz) 
Park

Ransiek

Rolletschke

C. Schröder

Tiedemann, GmbH-Strafrecht

Tiedemann,

Wirtschaftsstrafrecht

Tiedemann,

Wirtschaftsstrafrecht

Tipke/Kruse

Tipke/Lang

Wabnitz/Janovsky/Schmitt

Weyand/Diversy

Wittig

Ziouvas
Kapitalmarktstrafrecht, Handkommentar, 5. Aufl. (2019)

Unternehmensstrafrecht (1996)

Steuerstrafrecht, 5. Aufl. (2019)

Handbuch Kapitalmarktstrafrecht, 4. Aufl. (2019)

GmbH-Strafrecht (§§ 82-85 GmbHG und ergänzende Vorschriften), 5. Aufl. (2010) (Sonderausgabe aus der 10. Aufl. des Kommentars zum GmbHG von Scholz, Bd. III 2010)

Wirtschaftsstrafrecht, 5. Aufl. (2017)

Wirtschaftsstrafrecht in der Europäischen Union. Rechtsdogmatik - EU Rechtsvergleich - Rechtspolitik (Freiburg-Symposium), hrsg. v. Tiedemann (2002)

Abgabenordnung, Finanzgerichtsordnung. Kommentar zur AO und FGO

(ohne Steuerstrafrecht), Loseblatt. 156. Akt. (2019)

Steuerrecht, 23. Aufl. (2018)

Handbuch des Wirtschafts- und Steuerstrafrechts, 5. Aufl. (2019) (vormals Wabnitz/Janovsky)

Insolvenzdelikte, 10. Aufl. (2016)

Wirtschaftsstrafrecht, 4. Aufl. (2017)

Das neue Kapitalmarktstrafrecht (2006)

\section{Zivilprozessrecht und Insolvenzrecht}

Baumbach/Lauterbach/

$\begin{array}{ll}\text { Albers/Hartmann } & \text { s. BLAH } \\ \text { BLAH } & \text { Zivilprozessordnung, 77. Aufl. (2019) } \\ \text { FK-InsO } & \text { Frankfurter Kommentar zur Insolvenzordnung, hrsg. v. } \\ & \text { (2018) } \\ \text { HK-InsO } & \text { Heidelberger Kommentar zur Insolvenzordnung, hrsg. } \\ & \text { 9. Aufl. (2018) } \\ \text { Jaeger } & \text { Insolvenzordnung, Großkommentar, hrsg. v. Henckel/ } \\ \text { KPB } & \text { InsO - Kommentar zur Insolvenzordnung, Loseblatt. 79. } \\ \text { Kübler/Prütting/Bork } & \text { s. KPB } \\ \text { Leonhard/Smid/Zeuner } & \text { Insolvenzrechtlicher Vergütungsverordnung (InsVV), Kor } \\ & \text { Leonhard/Smid/Zeuner, (2014) } \\ \text { MK-InsO } & \text { Münchener Kommentar zur Insolvenzordnung, 3. Aufl. } \\ \text { MK-ZPO } & \text { Münchener Kommentar zur ZPO, 5. Aufl. (ab 2016) } \\ \text { Musielak/Voit } & \text { ZPO - Zivilprozessordnung, Kommentar, 14. Aufl. (2017) } \\ \text { Rattunde/Smid/Zeuner } & \text { Insolvenzordnung (InsO), Kommentar, hrsg. v. Rattunde/ } \\ & \text { 4. Aufl. (2018) (vormals Leonhard/Smid/Zeuner) } \\ \text { Rosenberg/Schwab/Gottwald } & \text { Zivilprozessrecht, 18. Aufl. (2018) } \\ \text { Stein/Jonas } & \text { Kommentar zur Zivilprozeßordnung, 23. Aufl. (2014 ff) } \\ \text { Thomas/Putzo } & \text { ZPO - Zivilprozessordnung, 40. Auflage (2019) } \\ \text { Zöller } & \text { Zivilprozessordnung, Kommentar, 33. Aufl. (2020) }\end{array}$

\section{Sonstiges (einschließlich Arbeits- und Sozialrecht, Völkerrecht und Waffenrecht)}

Bieneck

Brownlie

Corpus Juris
Handbuch des Außenwirtschaftsrechts mit Kriegswaffenkontrollgesetz, hrsg. v. Bieneck, 2. Aufl. (2005)

Principles of Public International Law, 8. Aufl. (2012)

The implementation of the Corpus Juris in the Member States/La mise en œuvre du Corpus Juris dans les Etats Membres, hrsg. v. Delmas-

Marty/Vervaele (2000); Deutsche Version der Entwurfsfassung von 1997: Delmas-Marty (Hrsg.), Corpus Juris der strafrechtlichen Regelungen zum 
Dahm/Delbrück/Wolfrum

ErfK

Fuchs/Preis

Gerold/Schmidt

Götz/Tolzmann

Hanau/Adomeit

Hauck/Noftz

Herdegen

Hoeren/Sieber/Holznagel

HwbRW I-VIII

Ipsen

Kaiser/Günther/Taupitz

KassKomm

Keller/Günther/Kaiser

Kröger/Gimmy

Linens/Korte

Lüder/Vormbaum

Multimedia-Recht

Rebmann/Uhlig

Seidl-Hohenveldern

Seidl-Hohenveldern/Stein

Shaw

Steindorf

Strupp/Schlochauer

Thüsing

Tolzmann

Ulsamer LdR

Verdross/Simma

Vitzthum/Proelß

Waltermann

Wannagat

Werle/Jeßberger
Schutz der finanziellen Interessen der Europäischen Union, Deutsche Übersetzung von Kleinke und Tully, Einführung von Sieber (1998)

Völkerrecht, 2. Aufl., Band I/1 (1989), Band I/2 (2002), Band I/3 (2002)

Erfurter Kommentar zum Arbeitsrecht, 20. Aufl. (2019)

Sozialversicherungsrecht, 2. Aufl. (2009)

Rechtsanwaltsvergütungsgesetz, 24. Aufl. (2019)

Bundeszentralregistergesetz, Kommentar, 4. Aufl. (2000); Nachtrag (2003)

Arbeitsrecht, 14. Aufl. (2007)

Sozialgesetzbuch - Gesamtkommentar, hrsg. v. Hauck/Noftz, Loseblatt

(Stand $2019 \mathrm{ff}$ )

Völkerrecht, 18. Aufl. (2019)

s. Multimedia-Recht

Handwörterbuch der Rechtswissenschaft, hrsg. v. Stier-Somlo u.a., Bd. 1 (1926), Bd. 2 (1927), Bd. 3 (1928), Bd. 4 (1927), Bd. 5 (1928), Bd. 6 (1929), Bd. 7 (1931), Bd. 8 (1937) (unter dem Titel: Die Rechtsentwicklung der Jahre 1933 bis 1935/36)

Völkerrecht, 7. Aufl. (2018)

Embryonenschutzgesetz, Juristischer Kommentar, 2.Aufl. (2014)

Kasseler Kommentar Sozialversicherungsgesetz, Loseblatt, 103. Aufl. (2019)

Embryonenschutzgesetz, Kommentar (1992)

Handbuch zum Internetrecht (2012)

Wehrstrafgesetz, Kommentar, 5. Aufl. (2012) (vormals Schölz/Lingens)

Materialien zum Völkerstrafgesetzbuch: Dokumentation des Gesetzge-

bungsverfahrens (2002)

Handbuch Multimedia-Recht, hrsg. v. Hoeren/Sieber/Holznagel, Loseblatt.

48. Aufl. (2019)

Bundeszentralregister, Gewerbezentralregister, Verkehrszentralregister und ergänzende Bestimmungen, Kommentar (1985)

Lexikon des Rechts - Völkerrecht, 3. Aufl (2001)

Völkerrecht, 12. Aufl. (2009)

International Law, 8. Aufl. (2018)

Waffenrecht, Kurzkommentar, 10. Aufl. (2015)

Wörterbuch des Völkerrechts, 2. Aufl., Band 1 (1960), Band 2 (1961), Band 3 (1962)

AÜG - Arbeitnehmerüberlassungsgesetz, Kommentar, hrsg. v. Thüsing, 4. Aufl. (2018)

Bundeszentralregistergesetz, 5. Aufl. (2015)

Lexikon des Rechts: Strafrecht, Strafverfahrensrecht, hrsg. v. Ulsamer, 2. Aufl. (1996)

Universelles Völkerrecht, 3. Auflage (2010)

Völkerrecht, 8. Aufl. (2019)

Sozialrecht, 13. Aufl. (2018)

Sozialgesetzbuch I/IV/X, hrsg. v. Eichenhofer/Wenner (2012)

Völkerstrafrecht, 4. Aufl. (2016) 
